\title{
CONHECIMENTO E REPRESENTAÇĀO EM EL SEÑOR PRESIDENTE
}

LEONILDA AMBROZIO

\section{RE-PRESENTAÇÃo E CONHECIMENTO}

Enquanto a mimese sempre pressupõe uma contigüidade ao real, ainda que não imitação ou cópia, a re-piesentação supõe o texto literário com "planos simultâneos, isto é, desdobráveis em camadas"1). Desta maneira o conceito de representação como "apresentação intencional de um objeto, quer in:electual, quer sensível, pertencente aos sentidos externos ou internos"2), limita-o: o signo traria em si o representado. Para a concepção derrideana o signo grafado não pode apresentar-se como presente: ele re-presenta o presente. Assim é que a re-presentação dissimula toda a problemática do presente em ausência. Ela desvenda e ao mesmo tempo esconde. Retorna àquìlo que está ausente, porém em estado latente no texto. Há que se busca- "escondido", a verdade, por detrás da cena. Derrida é contrário à fícção logocêntrica que considera os signos como comandados por convençōes absolutas. A forma verbal não nos remete a um único significado: os traços nas seqüências verbais nos levam a outros significados ${ }^{3}$ ). O que se há de considerar é o prefixo re que implica uma retomada ativa daquilo que se apresenta. Se toda re-presentação está em relação com qua!quer out:a coisa (sujeri:o ou objeto) diremos que ela está, então, relacionada à faculdade de conhecer. E a re-presentação, nesse sentido, a sintese do que se apresenta, é o próprio conhecimento.

\section{A RE-PRESENTAÇÃO EM EL SENTOR PRESIDENTE}

Partindo do conceito de Delacroix de que "el hombre no percibe ni conoce, no se percibe ni se conoce en tanto construye el lenguaje"4)

I LIMA, Luis Costa. Projeçōes do idcológico. IN: ENCONTRO NACIONAL,DE PROFESSORES DE LITERATURA, 1.0, ,Rio de Janeiro, Pontifícia Universidade Catolica, 1974, p. 18.

2 BRUGGer, Walter. Dicionário de filosofia. São Paulo, Herder, 1962.

3 GLOSSÁR:O de Derrida. Sup. Silviano Sartiego. R:o de Janeiro, Francisco Alves, 1976. p. 80-81.

4 DICCIONÁRIO del lenguaje fi.osófico. Dir. Paul Foulquié. Barcelona, Labor, 1967, p. 895. 
temos que a re-presentação só se concretiza enquanto se faz linguagem. Tudo se funda se ergue, se revela, se re-presenta por meio desse código. A frase heideggeriana sinteliza esta afirmativa quando diz que ela é a "casa do Ser". Tudo é na linguagem, portanto, representação e conhecimento se instauram através dela,

Podemos dizer que Miguel Angel Astúrias, junto com Alejo Carpentier, é o arauto, na liieratura de nosso continente ibero-amelicano, da libe:dade criadora da palavra, sendo um dos primeiros a romper a linha entre significado e signigicante, pois o signo verkal não é "uma entidade una, mas sim umá cavidade de ressonância"5). Através do eixo sintagmático há que se buscár o que se oculta na construção paradigmática, numa tentativa de preencher 0 vazio, o não-dito.

Romance concebido na década de vinte, El señor presidente representa uma ruptura com o sis'ema tradicional de narrativa. De fundamental importância para isto foi a descoberta do método surrealista como método de conhecimento. A realidade deixou de ser considerada comio um fenômeno que se repetia na continuidade do lempo e espaço para ser algo mais abarcante. Tudo isso deveu-se iambém às descobertas de Freud, a descoberta de que o sonhado existe na mesma coniinuidade que o vivido sendo, portanto, parte integ:ante de nossa realidade. Por outro lado, os estudos de Jung sobre o inconsciente coletivo levaram Astúrias ao estudo da mitologia e religião dos maias. Dessa maneira, a re-presentação da realidade em El señnor presidenle u!trapassou os limites do "real" aparente e transcende ao nivel do irreal, um irreal que é ao mesmo tempo a projeção desse real. Temos aqui as próprias palavras de Astúrias:

Mis novelas siguen la corriente del "realismo mágico"... Mi realismo es "mágico" porque él revela un poco del sueño como lo conciben los surrealistas. Tal como lo conciben también los Mayas en sus textos sagrados. Leyendo estos últimos yo me he dado cuenta que existe una realidade palpable sobre la cusl se injerta una otra realidad, creada por la imaginación, y que se envuelve de tantos de:alles que llega a ser tan "real" como la otra"0).

Como vimos, para Astúrias, o irreal, o mágico, podem ser tão possiveis quanto o real. Através de palavras instaura um mundo

5 LIMA, Luis Costa. Projeçōes..., p. 18.

6 JOZEF, Bella. O espaço reconquistado. Patrópolis, Vozes, 1974, p. 33. 
onde as fronteiras entre um e outro inexistem. Em El señor presidente cria um ambiente de sonho, lembrando a personagem calderoniana Segismundo que vivia sem livre arbítrio, dominado por seu pai Basilio, sem saber exatamente se vivia ou sonhava. Também as personagens asturianas nāo têm vida própria, são seres au'ômatos. Vivem num mundo angustiante e sem saída. $O$ poder as dirige.

2. 1. O mito cosmogônico

Dos três discursos de re-presentação (literário, mítico e onírico) demos destaque as segundo por pretendermos um estudo do mito cosmogônico, uma vez que em El señor presidente a re-presentação da realidade é uma repetição da Criação do Mundo.

Em realidade, este romance se apoia mais na ideologia do que propriamente no mito. Porém, sem dedicarmo nos ao estudo da ideologia, vemos que no mítico é colocada a questão do poder a qual procuraremos demonstrar a:ravés da figura de senhor presidente. A ausência de características psicológicas do presidente vai contribuir para a configuração do a:quétipo do Mal.

Seme'hante ao mito, a situação apresentada em El señor presidente pode repetir-se, da mesma maneira, em diferen es lugares. Não há localização exata, nem c:onologia determinada. Tudo é reoresentado a:quetipicamente. Atrávés de uma supra-realidade, temse a repetição de um real existente. A propósi o, transcrevemos as palavras de Anatol Rosenfeld:

Na dimensão mítica, passado, presente e futuro se identificam: as per'sonagens são, por assim dizer, abertas para o passado que é presente que é futuro que é presente que é passado - aberłas não só para o passado individual e sim o da humanidade: confundem-se com seus predecessores remótos, são apenas manifestações fugazes, máscaras momentâneas de um processo eterno que transcende não só o indivíduo e sim a p־ópria humanidade: esta, reintegrada no Arqui-Ser, que a ultrapassa e abarca, é par:e da luta eterna entre as forças divinas e demoniacas; é portadora de uma mensagem sobre-humana; ergue-se prometeicamente contra as divindades; é expulsa da unidade original; sof:e a tortura de Sísifo num mundo absurdo; vive a frust:ação do homem que almeja chegar ao Castelo dos poderes insondáveis, etc. Essim, em Ulysses transparecem, através das máscaras de Bloom, Dedalus e Molly, as personagens míticas de Ulisses. Te- 
lêmaco e Penépolè).

A cosmogonia segundo Miicea Eliade, é o mode'o fundamen:al de toda a situação criadora pois tudo o que a humanidade faz é repetição do gesto do criador inicial. Para isso é necessário não somente conhecer o "começo" como também integrar-se no momenio em que delerminäda coisa foi criada. Origem e criação se correspondem ${ }^{8}$ ). O conhecimento de que houve um começo após o caos inicial dá a cerieza de um novo começo e isto está patente co final de El señor presidente. A criação do mundo se sucederá uma Via-Crucis e um Apocalipsis. O final simbólico de um mundo, cela destruiçāo ou morle de váriás personagens, longe de ser uma visão nihilista, represenia, através da sob:evivência de um estudanle, a esperança de um racomeşo depois do caos.

\subsubsection{A inversão do Gênesis}

O primeiro pa:ágrafo de El señor presidente evidencia a re-preseniação da cilação de um mundo atrávés da palavra. A primeiia, após reticências iniciais (que poderiam esłar representando as trevas antes da luz) é um verbo.

Três acepções de $v^{2} c^{\circ} o^{9}$ ) cabe:iam na in'erprełação:

a) como palavia, vecábulo: fudo vai ser a partir dela, assim tamLém a re-presentação;

b) como a segunda pessoa da Santíssima Trindade, encarnada em Jesus Cris:o. O senhor aresidente será comparado no capítulo XIV como Jesus, ambos filhos do povo: "-Hijo del pueblo...!", "-Como Jesús, hijo del pueblo..." (SP, 9710)

c) como a sabedoria elerna Quem säbe tudo tem o Poder, é o deus.

Sobre a terceiza acepçāc, temos que frisar na primeira linha do parágrafo a evocação a "Luzbe!", o príncipe dos anjos rebeldes, o aue se rebelou contra Deus por não possuir também a ciência, o conhecimento. O mundo que re-cria Astúrias é um mundo ao avesso, é o negativo ou a inversão da narração do Gênesis. E a metáfora r.o Terceiro Mundo onde o medo, o terror, a miséria, substituem o paradisíaco.

7 ROSENFEld, Anatol. Texto/Confexto. Sāo Pavio, Perspectiva, 1973, 1p. 90.

8 ELIADE. Mirces. Mito e realidado. São Paula, Perspectiva, 1972, p. 34.

9 FERRERA, Aurélio Buarque de Holenda. Novo dicionário da língua portuguasa. Rio de Janeiro, N=va, Fronteira, 1975.

10 ASTÚRIAS, Miguel Angel. El señor presidente. Buencs Aires, Losada, 1976. As remissö́es a este livro se:äo convencionades ,com as iniciais SP. 
O "fiat lux" da narração bíblica é invertido para um apelo a. essa mesma luz, seguida como reforço da própria idéia de lamento. A sonoridade com a vogal u nos remete a sombras, à escuridão, à noite, por extensão, ao Caos primordial. Por outro lado, ainda. o primeiro parágrafo nos leva a um mundo de magra, de cabala, mundo da noite, onde se evoca o Diabo. A antítese luz/sombra, representa uma dupla realidade. A dicotomia entre o Bem e o Mal, entre Deus e Diabo aparece no contraste entre a evocação a "Luzbel" e o rumor dos sinos chamando à oração:

... Alumbra, lumbre de alumbre, Luzbel de piedralumbrel Como zumbido de oídos pesistía el rumor de las campanas y la oración, maldoblestar de la luz en la sombra, de la sombra en la luz. Alumbra, lumbre de alumbre, Luzbel de piedialumbre, sobre la podredumbiel Alumbra, lumbre de alumbre, sobre la podredumbre. Luzbel de piedralumbre! Alumbra, alumbia, lumbre de alumbre..., alumbre..., alumbra..., alumbra, lumbre de alumbre..., a!umbra, alumbre...! (SP, 7$)$.

O mal materializa-se na figura do diabo. Este, mais que o corihecimento, tem a ordem do destino. Portanto, a vida dos habitan'es desse mundo está em suas mãos, assim como, segundo as concepção cu istã, somos guiados por Deus: Vejamos:

Le démon symbolise une illumination supérieure aux normes habituelles, permettar.t de voir plus loin et plus surement, d'une façon irrédisctible aux arguments. II autorise même à violer les règles de la raison, aux nom d'une lumière trancendante qui est non seulement de l'ordre de la connaissance, mais aussi de l'ordre du des$\operatorname{tin}^{11}$.

Outro indício que nos levou a interpretar o tex'o como a criação do Terceiro Mundo (um inferno e não um céu) foram as datas. 4 primeira parte do livro (21, 22 e 23 de abril) somada com a segunda $(24,25,26$ e 27 de abril) perfazem o total de 7 dias: simbolicamente o tempo que durou a criaçōo. A terceira parte vem sob a denominação de "serr.anas, meses, años..." (seria a eternidade subentendida através das reticências, e, por extensão, a continuidade do Mal ou a Via-Ciucis do povo).

\subsubsection{O "deus" e o "anjo"}

11 CHEVAlieR, Jean \& GHEEBRANT, Alain. Dictionnaire des symboies. Paris, Seghers, 1973, p. 185. 
A própria metáfora do tíulo é outro dado de fundamental importáncia. O senhor presidente, cuias maq̣ inaçōes estruturam toda a narrativa, aparece como um deus, não to:almente revelado, posto que manipula seus subordinados (dissimulando) do alto de seu palácio: poder e distanciamento. Estranha figura, contrapõe-se à figura de um deus, pois já tras as marcas do tempo; é um ser mortal. Por outro lado, seu aspecto físico é todo negro, como um demonio:

El Presidente vestía, como siemnre, de luto riguroso: negros los zapatos, negro el traje, negra la corbata, negro el sombreio que nunca se quitaba; en los bigotes canos, peinados sobre las comisuras de los labios, disımulada las encías sin dientes, tenía los carrillos pellejudos y los párpados coms pellizcados (SP, 36).

Entretanto, em sua representação em um retrato a intenção é fixar no tempo e no esçaço as raracterísticas de um deus (juventude, fortaleza, vitória):

... y un retrato del Señor Presiderite, echado a perder de joven, con ferrocarriles en los hombros. como charreteras, y un angelito dejándole caer en la cabeza una corona de laurel. Ret:ato de mucho gusto (SP, 39).

Símbolo do Poder, o Senhor Presidente, tal como um deus, é o dono da palavra e possui o seu anjo.

Miguel Cara de Ángel. "el favorito", é o porta-voz da palavra. Há em seu nome a reduolicação de uma referência pois ele é Miguel, "o arauto". "o revelador" e ao mesmo tempo, tem cara de anjo. Seria ele, portanto, um simulacro do Anjo Miguel. Por outro !ado, o aposto "belo y malo como Satán" nos leva a uma inversão de valores. Se o tínhamos como simulacro de anjo, seria agora uma ciissimulação do diabo? Se Satã é a negaçāo de Deus, seria ele a regação do Senhor Presidente? A verdade é que ele é visualizado como se fosse um anjo pelo lenhador que presta socorro a Pelele, fugitivo, na mata.

El leñador volvió la cabeza para responder y por poco se cae del susto. Se le fue el aliento y no escapó por no soltar al herido, que apenas se tenía en pie. El que le hablaba era un ángel: tez de dorado mármol, cabellos rubios, boca pequeña y aire de mujer en violento contraste con la negrura de sus ojos varoniles. Vestía de gris. Su traje, a la luz del crespúculo, se vela como una nube. Llevaba en las manos finas una caña de bambú 
muy delgada y un sombrero limeño que parecía una paloma (SP, 27)

Propósito ou coincidência, há que se ressaltar a semelhança de nomes e de missão entre Miguel Cara de Ángel e Miguel Ângel Astúrias, ambos arautos da palavra.

Ao contrário do presidente, Miguel é bonito fisicamente. Suas características, conforme já vimos, são as de um anjo: era loiro, o que parece evidenciar um ser vindo de "outro mundo" posto que o tipo físico do latino-americano é moreno. Era mau, pela estrutura do Inferno onde vivia. Ao encontrar Camila, após uma maquinação satânica do Poder, humaniza-se.

Miguel Cara de Angel como adquiriu o conhecimenio (conhecer é discernir) soube distingüir entre o Bem e o Mal, foi levado à morte, assim como Adão e Eva perderam a vida eterna após provarem da Arvore da Vida, isto é, desobedeceram as ordens do Senhor. A reduplicação desse mito também aparece em um sonho de Pelele:

... Y cantaba en el pino un pájaro que a. la vez que pájaro era campanita de oro:

- Soy la Manzana-Rosa del Ave del Paraíso, soy la vida, la mitad de mi cuerpo es mentira y la mitad es verdad; soy rosa y soy manzana, doy a todos un ojo de vidrio y un ojo de verdad: los que ven con mi ojo de vidrio ven porque sueñan, los que ven con mi ojo de verdad ven porque miranl Soy la vida, la Manzana-Rosa del Ave del Paraíso; soy la mentira de todas las cosas reales, la realidad de todas las ficciones! (SP, 24).

E interessante notar que quando Cara de Angel pressente sua própria morte, tem uma visão. Quem lhe aparece é Tohil, o gigante que exigia sacrificios humanos, sendo, portanto, uma re-piesentação do presidente. Explica-se: várias vezes, inocentes foram sacrificados. Quem matasse um militar estava coméendo um sacrilégio e todos deveriam pagar pelo pecado. $O$ poder militar ea o próprio deus. A sacralização do poder, sintetizado na figura do presidente, temos, por exemp!o no delírio de Cara de Anjo que o vê como um "ser dorado". Esta visão de um ser é multiplicada na visão que tem, diante do presidente, ao olhar a praça através da janela. Segundo Edward Lopes e Eduardo Penuela Canizal as quatro sombras seriam "a representação mítica dos quatio gigantes cósmicos", presentes 
na mitologia maia ${ }^{12}$ ):

Una palpitación subterránea de reloi subterráneo que marca horas fatales empezaba para Cara de Ángel. Por una ventana abierta de par en par entre sus cejas negras distinguía una fogata encendida junto a cipresales de carbón verdoso y tapias de humo blanco, en medio de un patio borrado por la noche, amasia de centinelas y almácigo de estrellas. Cuatro sombras sacerdotales senalaban las esquinas del patio, las cuatro vestidas de musgo de esquinas del patio, las cuatro vestidas de musgo de adivinaciones fluviales, las cuatro con las manos de piel de rana más verde que amarilla, las cuatro con un ojo cerrado en parte de la cara sin tiznar y un ojo abierto, terminado en chichita de lima, en parte de la cara comida de oscuridad. (SP, 261).

\subsubsection{Do Gênesis à Via-Crucis}

A Via-Crucis dos seres apresentados em $\mathbf{E}$ señor presidente é representada por todo o sofrimento, dores, gritos, gemidos, medo, perseguição, apelos desesperados:

- ;Ay, mis o...vaaaAAArios! ;Ay mis ovAAArios!

;Ay, mis 0...vaaAAAAArios! ;Mis ovarios! ;Ay... mis ovarios! ;Ay...! (SP, 162).

La noche entera estuvo quejándose quedito y recio, quedito y recio como un perro herido:

... Erre, erre, ere... Erre, erre, ere...

Erre - e - e:re - e - erre - e - erre...., e - erre, e - erre ... (SP, 20).

Fato curioso é que a própria fuga de Pelele é representada por uma cruz, a'ravés das linhas horizontal e ve:tical: "Fuga vertiginosa, horizontal, vertical, oblicua, recién nacida y muerta em espiral... (SP, 20). As let:as inscritas na cruz de Cristo aparecem em: ;I-N-RIdiota! ;I-N-R-Idiota! (SP, 20). $O$ apelo à mãe nos remete à Madre Dolorosa.

O símbolo da cruz aparece também junto a outros elementos que dizem respeito ao sacrificio de Cristo como: crucificar, ressuscitar, pregai, pregos:

12 LOPES, Edward \& CANIZAL, Eduardo Penuela. Conlextos míticos na literatura hispano-americana-1. O Estado do S.,Paulo, 9 mai 1970. Supl. Lit. P. I. 
Se tocó un pie con otro. Le comía la falta de clavo en la cruz en que estaba (SP, 142).

Los presos seguíam pasando... Ser ellos y no ser ellos los que a su paso se alegiaban en el fondo de no ser ellos... Al tren de carretillas de mano sucedian el grupo. de los que cargaban al hombro la pesada cruz de las herramientas $y$ atrás, en formación, los que arrastraban el ruido de la serpiente cascabel em la cadena (SP, 288).

A toriura humana é dissimulada na brincadeira dos meninos torturando besouros. Os seres humanos támbém não passam de insetos:

Grupos de muchachos se divertían en las esquinas con los ronrones que atraídos por la luz revoloteaban alrededor de los focos eléctricos. Insecto cazado era sometido a una serie de torturas que prolongaban los más belitres a falta de un piadoso que le pusiera el pie para acabar de una vez. (SP, 56).

Todo esse estado de coisas é agravado por um misticismo, por um fatalismo religioso, que os fazem conformados com o destino. Tudo é vontade de Deus (na realidade, vontade do poder). Vejamos:

La impresión de los barrios pobres a estas horas de la noche era de infinita soledad, de una miseria sucia con restos de abandono oriental, sellada por el fatalismo religioso que le hacla voluntad de Dios. Los desagües iban llevándose la luna a flor de tierra, y el agua de beber. contaba, en las alcantarillas, las horas sin fin de un pueblo que se creía condenado a la esclavitud $y$ al vicio $(5 P, 56)$.

\subsection{O giotesco}

As deformações físicas( surdos-mudos, cegos, aleijados, coxos, idiotas) co'ocam estes seres na categoria de mediadores entre o Ser e o Não-Ser. Representam simbolicamente a própria deformação da sociedade onde vivem. Junto a estes aparece o grotesco, não no sentido do cốmico, mas no do trágico. Segundo Kayser, aparece onde falta ao homem uma diretriz para sua vida, sendo assim, a manifestação de uma angústia ${ }^{13}$ ). O grotesco é o que foge, o que transgride à normalidade humana. É neste sentido que estão as personagens asturianas: seres autômatos, sem identidade, angustiados,

13 KAYSER, Wolfgang. Lo grotesco: su configuración en fintura y literafura: Buanos Aires, Edit. Nova, 1964, p. 225. 
fora da pirâmide social. Mais que isso, são comparados a animais. Para ilustrar citamos alguns exemplos dos muitos que aparecem ao longo da narrativa: "chillo como un mono herido" (p. 8); "como un perro junto a la hembra em brama" (p. 152); "las diez espuelas de sus dedos" (p. 53); "reía con cacareo de ave doméstica" (p. 128); "los pordioseros se encogieron como gusanos" (p. 11).

O grotesco aparece também nos apelidos, posto que estes seres não têm nome:

1. Pelele: a palavra significa a representação de uma figura humana feita com palha e retalhos e que serve como diversão. Seria, portanto, um fantoche, um ser sem personalidade. Na edição para a língua portuguesa aparece traduzido por "Palhaço".

2. Marrana: é o feminino de "marrano", isto é, porco. Por dedução Marrana seria uma mulher sem asseio.

3. Mosco: um inseto, o mosquito. A personagem tinha somente até o tórax, pois faltavam-lhe as duas pernas.

4. Patahueca: apelido formado de duas palavras: o substantivo "pata" e sua qualificaçāo "oca". E o apelido de um coxo.

Pode-se dizer que todos os personagens não pertencentes à classe média. ou alta possuem apelidos: Lengua de Vaca, Chabelona, Viuda, Chón Dienłe de Oro, Masacuata, as prostitutas: Mojarra, Chata, Negra China, Lombriz, Paloma, Patuda, Mielconsebo, Sintripas, Bombasorda, etc.

\section{CONCLUSĀO}

São inesgotáveis os dados fornecidos por esta representação de um mundo em El señor presidente. Através da desestruturação desvendamos o que está dissimulado na ante-cena. A re-presentação nos levou ao conhecimento de um mundo dominado pelo Mal, derrotado, cuja esperança está no estudante, o único que se salvou por não estar integrado no Sistema. Isto reforça o mito cosmogônico de que há sempre uma luz depois do caos. Talvez o estudante seja um novo anjo, não com o destino de Miguel Cara de Ángel ligado ao Sistema, mas o anjo da palavra livre, o próprio Miguel Angel Astúrias. Testemunha e conhecedor de um mundo, também nos levou ao conhecimento dele através da re-presentaçäo. ,

\section{RESUMEN}

Por medio del discurso mítico se desvendó to re-presentación de una cosmogoría al revés en El Señor Presidento: la creación del Tercer Mundo. 